\title{
Potenciar una educación artística viable a través de la arquitectura
}

\section{Promotion of a Viable Art Education Through Architecture}

\author{
Beatriz Gabriela Tomsic Cerkez \\ Facultad de Pedagogía. Departamento de pedagogía del arte. \\ Universidad de Ljubljana, Eslovenia. \\ beatriz.tomsic@pef.uni-lj.si
}

Recibido: 14 de junio de 2011

Aprobado: 15 de febrero de 2012

\begin{abstract}
Resumen
Si tenemos en cuenta el papel de la educación y sus implicaciones en la formación de un usuario crítico y consciente de la arquitectura, es evidente que el desarrollo de estrategias educativas relacionadas con nuestro espacio común es fundamental. Debemos reflexionar sobre cómo desarrollar programas adecuados a todos los niveles educativos para promover actitudes responsables con el espacio común, que abarquen todos los aspectos del desarrollo sostenible, permitiendo al mismo tiempo una gran libertad con respecto a los aspectos formales de la arquitectura. Las ideas presentadas en el artículo se apoyan en una investigación empírica sobre la imagen de la arquitectura y el medio ambiente, que se realizó entre estudiantes de la escuela secundaria. La investigación se basó en la idea de que una de las actitudes críticas hacia el mundo más eficiente es desarrollar un vínculo incondicional de la obra de arte con las condiciones de la vida cotidiana. Esa es la razón por la que parte de las actividades dentro de la investigación se refieren al reciclaje de espacios arquitectónicos. Los resultados muestran una imagen de la arquitectura muy heterogénea, que a veces sobrevalora los contrastes y la originalidad, sin tener demasiado en cuenta la tradición.
\end{abstract}

Palabras Clave: educación artística, arquitectura, percepción del espacio, imagen de la arquitectura.

Tomsic Cerkez, B. G. (2012): Potenciar una educación artística viable a través de la arquitectura. Arte, Individuo y Sociedad, 24(2) 251-268

\begin{abstract}
If we consider the role of education and its implications in the formation of a critical and conscious user of architecture, it is obvious that the development of educational strategies related to our common space and environment become fundamental. The comprehension of the concept of sustainable development is essential. Therefore, it is worth reflecting on how to develop proper programs at all educational levels to promote critical and responsible attitudes towards the common environment covering all the aspects that should shape the concepts of sustainable spatial and environmental development, enhancing at the same time great freedom regarding the formal aspects of architecture.

The ideas presented in the article are supported by an empirical research on the image of architecture and the environment, held among secondary school students. The research based on the idea that one of the most efficient critical attitudes towards the world would be to develop an unconditional tie of the art work with everyday life conditions. That is why part of the activities within the research was devoted to recycling relevant architectural spaces. The results show a very heterogeneous image of architecture in the eyes of the students which sometimes overvalues contrasts and originality, disregarding tradition. Key Words: art education, architecture, spatial perception, the image of architecture.
\end{abstract}

Tomsic Cerkez, B. G. (2012): Promotion of a Viable Art Education Through Architecture. Arte, Individuo y Sociedad, 24(2) 251-268 
Sumario: 1. Introducción, 2. El contexto de la investigación 1: El desarrollo sostenible y la arquitectura., 3. El contexto de la investigación 2: Concepciones sobre el espacio arquitectónico, 4. La Arquitectura, la percepción y el medio ambiente, 5. Educación para la arquitectura, reciclaje del espacio urbano, 5.1. Aplicación pedagógica: Métodos y desarrollo, 5.2. Resultados, 5.3. Discusión, 6. Conclusión: La conservación de la energía cultural. Referencias.

\section{Introducción}

El equilibrio entendido como un estado balanceado del ser es un apoyo conceptual fundamental en momentos en que conceptos dialécticos tales como "global/local", "propio/ajeno" o "tradición/innovación" están directamente involucrados en el discurso y la práctica de la arquitectura. Es interesante notar, que estos procesos no afectan a otros campos del arte, al menos no en la misma forma que en el caso de la arquitectura, lo que demuestra las potencialidades y el poder que tiene la misma en los aspectos ideológicos, financieros, sociales, culturales e históricos de la sociedad. Los mecanismos de construcción de los pares de conceptos dialécticos antes nombrados, siguen caminos diferentes: reflejan el contexto de procesos históricos, culturales y al mismo tiempo, la práctica concreta y la evaluación de la arquitectura.

Si tenemos en cuenta el papel de la educación y sus implicancias en la formación de un usuario de la arquitectura crítico y consciente, es evidente que el desarrollo de estrategias educativas relacionadas con nuestro espacio común y con el medio ambiente se vuelve fundamental. La comprensión del concepto de desarrollo sostenible, perdurable o sustentable es esencial. El desarrollo sostenible es un patrón de uso de los recursos, en este caso haciendo hincapié en el espacio construido y natural, que tiene como objetivo satisfacer las necesidades humanas, preservando el medio ambiente para que estas necesidades puedan ser satisfechas, no sólo en el presente, sino también para las generaciones futuras. En el campo de la ecología, la expresión describe cómo los sistemas biológicos pueden seguir siendo diversos y productivos a través del tiempo. Para los humanos significa la posibilidad de mantenimiento del bienestar a largo plazo, lo que a su vez depende del bienestar del mundo natural y el uso responsable de los recursos naturales. Esto requiere la conciliación de las demandas ambientales, sociales y económicas - los "tres pilares"de la sostenibilidad que no se excluyen mutuamente sino que deben reforzarse mutuamente.

En este contexto, nos podemos preguntar cómo los conceptos de armonía y orden espacial, que tienen un significado fundamental en la descripción de muchos fenómenos y procesos de carácter espacial, se entendían en el pasado y cómo se perciben hoy en día, a la luz de los actuales documentos, proyectos y realizaciones en este campo. Y además, de que manera desarrollar programas adecuados en todos los niveles educativos para promover actitudes críticas y responsables con el medio ambiente común, que abarquen todos los aspectos que deben dar forma a los conceptos de desarrollo sostenible del medio ambiente, permitiendo al mismo tiempo una gran libertad con respecto a los aspectos formales de arquitectura.

También es necesario tener en cuenta las consecuencias del fenómeno de la universalización y sus efectos perturbadores, por la difusión ante nuestros ojos de una "cultura básica de consumo masivo", como la llama P. Ricoeur (1985), con su 
“arquitectura rápida" extendiéndose por todos los países. Esta situación da testimonio del desarrollo y consumo de la arquitectura con una nueva definición de la función del arquitecto así como del individuo frente a la misma, lo cual testifica acerca de la importancia de esta problemática.

Las ideas presentadas en este trabajo se refuerzan con la presentación de una investigación empírica sobre la imagen de la arquitectura y el medio ambiente, que se realizó entre estudiantes de la escuela secundaria. La investigación, basada en la idea de que una de las actitudes críticas más eficientes hacia el mundo sería desarrollar un vínculo incondicional de la obra de arte con las condiciones de la vida cotidiana, argumentando que la posibilidad de correr el riesgo de una eventual incompatibilidad en las creencias respecto a las características y necesidades de nuestro espacio de vida común se fundamenta en la educación de »perceptores críticos« del medio ambiente en su conjunto, que deberían reaccionar frente a eventuales disonancias de una manera constructiva y responsable.

\section{El contexto de la investigación 1: El desarrollo sostenible y la arquitectura}

Siendo un tema que genera variadas discusiones, lo que es la sostenibilidad, cuáles deben ser sus objetivos y cómo se los pretende alcanzar queda abierto a diferentes interpretaciones. Para muchos ambientalistas la idea del desarrollo sostenible es una paradoja ya que el concepto de desarrollo parece implicar en todos los casos la degradación del medio ambiente. Algunas investigaciones parten de esta definición para argumentar que el medio ambiente es una combinación de naturaleza y cultura que integra capacidades multidisciplinarias e interpreta la diversidad cultural como el elemento clave de una nueva estrategia para el desarrollo sostenible.

La sostenibilidad requiere que las actividades humanas utilicen recursos naturales a una velocidad tal, que los mismos se puedan reponer de forma natural. En teoría, el resultado de la degradación ambiental a largo plazo es la incapacidad para sostener la vida humana. Esta degradación a escala global podría significar la extinción de la humanidad. También existen muchas críticas serias al concepto de desarrollo sostenible. M. J. Anderson (2002) sugiere que el verdadero propósito del desarrollo sostenible es contener el desarrollo económico en los países en desarrollo y con ello promover el control del crecimiento de la población. La autora sostiene que desarrollo sostenible ha seguido evolucionando, definido como protección de los recursos del mundo mientras que su verdadera agenda es el control de los recursos del mundo.

La geógrafa francesa S. Brunel en su obra "¿Quién se beneficia con el desarrollo sostenible?"(2008) hace una crítica de base al desarrollo sostenible, con su visión binaria del mundo, que se puede comparar con la visión cristiana del Bien y del Mal; una naturaleza idealizada, donde el ser humano es un animal como los demás o incluso un extraño. La naturaleza - como expresa el pensamiento de J. J. Rousseau - es mejor que el ser humano. Este es un parásito perjudicial para la naturaleza. Pero el ser humano es al mismo tiempo quien protege la biodiversidad, donde normalmente sólo los fuertes sobreviven. Por otra parte, la autora piensa que las ideas del desarrollo sostenible pueden ocultar una voluntad de proteccionismo de los países desarrollados para impedir el desarrollo de los demás países. 
Desde el punto de vista hermenéutico, tenemos que reflexionar sobre la cuestión del desarrollo sostenible, a fin de entender cómo crear una conexión entre una tradición incomprensible y una cultura que debe insistir en la conservación de ciertos elementos, en este caso, la conservación de determinados lugares que merecen una calificación y valorización adecuada.

En nuestra sociedad de "usar y tirar", siempre ha sido común pensar que es mejor derribar un edificio de edad a fin de poner algo brillante y nuevo, gastando energía, recursos y materias primas valiosas. Tiene mucho más sentido volver a utilizar un edificio viejo y reconstruir sólo las partes que sean necesarias. Tenemos una cierta familiaridad con el espacio de la ciudad, el saber que el horizonte que hemos conocido toda la vida no ha cambiado mucho nos da sensación de estabilidad y seguridad. Podríamos caminar del punto A al punto B observando los edificios, percibiendo en cualquier momento en que lugar estamos, porque los elementos que nos rodean no han cambiado.

Conservación, restauración y rehabilitación de la arquitectura causa mucha menos destrucción de los recursos naturales que una nueva construcción. Para apreciar esto, los arquitectos deben ser sensibles a la energía utilizada en la fabricación y montaje de los materiales necesarios para construir edificios nuevos, desde su origen hasta el final de su vida y su posterior reutilización. Las estadísticas revelan que la construcción de edificios consume el 40 por ciento de las materias primas que se mueven en la economía mundial cada año. Curiosamente, alrededor del 85 por ciento del total de la energía incorporada en los materiales se utiliza en su producción y transporte. Incluso antes de llegar al sitio de construcción, muchos materiales de construcción ya han consumido grandes cantidades de combustibles fósiles.

Si todos los "costos ocultos"se explicitaran en el balance general, indudablemente se percibiría el reciclaje de la arquitectura como la única estrategia racional para la gestión de los recursos materiales. Los métodos modernos de construcción son increíblemente derrochadores de recursos. Hasta el 25 por ciento del total de residuos generados en los Estados Unidos, India y otros países se atribuye directamente a la construcción y las actividades de demolición. Los diseñadores sensibles a las prácticas sostenibles deberían establecer un programa de reciclaje para reducir la cantidad de residuos sólidos de construcción y elegir materiales que se sean reciclables o reutilizables. Por el contrario, la reutilización y adaptación requiere mucha más mano de obra que la construcción nueva, ya que implica el reacondicionamiento de estructuras existentes para adaptarse a las necesidades de hoy en día. Esta dependencia de los recursos humanos alienta a la comunidad local a participar y, potencialmente, revive los aspectos vernaculares en la arquitectura. Esta actividad puede también recordarnos que la arquitectura vernácula es uno de los pilares de nuestra identidad.

\section{El contexto de la investigación 2: Concepciones sobre el espacio arquitectónico}

La definición del espacio arquitectónico ha sido a lo largo de la historia y especialmente a partir del Renacimiento, cada vez más vinculado al el producto de la proyección y la introyección subjetiva y por lo tanto se opone a la idea del espacio como 
un constante "contenedor"de las cosas y los cuerpos. Hoy en día, el mundo de la arquitectura ofrece una amplia gama de nuevas experiencias: profundas sombras, debido a las diferentes formas de ocupación del espacio, la pérdida de la idea de la fachada clásica y de la claridad y "legibilidad" de los principios con los que se diseñó el edificio, el uso de materiales "espejo", que transforman las condiciones del espacio arquitectónico interior y exterior en relación con el cuerpo humano. Un espacio sin barreras y casi sin previsibilidad poco a poco va reemplazando al espacio arquitectónico tradicional, centrado en el cuerpo humano.

Si nos atenemos a los recientes debates sobre la definición del espacio arquitectónico, debemos mencionar las ideas de A. Schmarsow, quien aboga por una especie de empirismo perceptual y habla del espacio, que no debe ser entendido sólo como un pasivo "contenedor" de nuestros cuerpos y de los edificios, sino que se define por dimensiones de relatividad, movimiento y entidad dinámica. La historia de la arquitectura es la historia del concepto del espacio por lo que está constantemente teñida por los cambios en nuestras actitudes respecto a el y las actualizaciones en la conceptualización del término. Las impresiones visuales, las imágenes producidas por las diferencias en el brillo y los colores son elementos primarios en nuestra percepción de un edificio. El ser humano reinterpreta la concepción empírica de la corporeidad y determina la forma del espacio interior y exterior que lo abraza. Sin embargo, la apariencia física óptica, y la espacialidad propia no crean la masa del edificio: sólo cuando la percepción del espacio, después del movimiento a través del mismo termina, las formas arquitectónicas pueden ser interpretadas, dice Schmarsow (Vidler, A. 2001).

S. Gieidion en su famoso libro "Espacio, Tiempo y Arquitectura" (2008) afirma que la invención de una nueva concepción del espacio fue el leitmotiv de la modernidad. Tal argumento fue apoyado por las vanguardias artísticas, con su escape de la historia, haciendo hincapié en la existencia de un espacio universal de la vida moderna, disolviendo el etiquetado rígido de los estilos para dar a la »nueva arquitectura« una base fundamental que le permitiese desarrollarse mediante la inclusión de nuevas dimensiones del tiempo y de la definición de una relación con la naturaleza y con el cuerpo humano diferente a la que existía hasta ese momento.

Dejando de lado las diferencias obvias, los efectos gráficos que ofrece el espacio digital contemporáneo, dependen profundamente de los experimentos de representación del espacio de la modernidad en formas que tienen consecuencias importantes para la teorización sobre la virtualidad, dice A. Vidler (2001). Si bien es cierto que la gama de técnicas de representación es aparentemente mayor, también es cierto que la estructura del espacio mismo comparado con el del período moderno ha cambiado poco. La perspectiva es aún la regla en entornos de realidad virtual, los objetos siguen siendo concebidos y representados de acuerdo a todas las convenciones de representación de las tres dimensiones que derivan de las prácticas del siglo XVIII y XIX. No hay muchas diferencias entre la ventana de Alberti y la pantalla del ordenador o la axonométrica de G. Monge y las simulaciones digitales. Lo que ha cambiado es la técnica de simulación, y lo más importante, la posición del sujeto o el tradicional "espectador" de la representación. Lo más cuestionable en este contexto es la naturaleza autogenerativa del programa informático y su ceguera ante la presencia del espectador. En este sentido, la pantalla no es una imagen, sino que se encuentra en una 
ubicación fija y no ambigua para el sujeto. Por otro lado, las nuevas investigaciones sobre las fuentes de la visión moderna confirman la existencia de diversas »técnicas del observador «, y se pone especial énfasis en la conciencia de las percepciones como un modelo que aporta a la construcción de una concepción coherente del mundo. El modelo no sólo es de carácter visual, ya que la percepción se mide en términos de proximidad y puntualidad. La percepción es una función que requiere actividad, productividad, flexibilidad, previsibilidad y funciona como operadora de la integración social, dice J. Crary en un libro con un título muy significativo: "Suspensiones de la percepción - Atención, espectáculo y cultura moderna" (2001). Esto significa, dice el autor, que la percepción es muy importante en el proceso de re-conceptualización del espacio y en la transformación de la cultura de masas, por lo que tenemos que considerar el problema de forma diferente a la que lo hacíamos hasta ahora, y admitir que la digitalización cambió la forma en que miramos y vemos el espacio. En cuanto a la importancia de la visión, O. Grau (2004) opina que lo que definimos como la realidad es sólo una declaración de lo que somos realmente capaces de observar y ver. El espectador de hoy, como resultado de la experiencia con la fotografía tradicional y digital, con el video y la televisión es más consciente de las condiciones de la perspectiva en las representaciones. La curvatura del espacio en las perspectivas implica un proceso específico de pensar la arquitectura, una meditación discursiva sobre el lugar del sujeto y de otros objetos en el espacio y sobre cómo la arquitectura entiende su posición en las reflexiones contemporáneas sobre el espacio. En este amplio contexto debemos ubicar el espíritu de este estudio: grandes cambios en las actitudes, la percepción y la evaluación de los acontecimientos en el mundo de la arquitectura, que se producen paralelamente a grandes cambios en el entorno educativo, con la aparición de un nuevo "alumno-espectador", que vive rápidos cambios funcionales en su vida y nuestra responsabilidad como pedagogos, administradores del sistema reproductivo del aparato ideológico que la escuela sigue necesariamente siendo.

\section{La Arquitectura, la percepción y el medio ambiente}

Desde el punto de vista semiótico, es indispensable desplegar el programa narrativo de cada lugar específico, así como sus elementos fenomenológicos con el fin de dilucidar cómo el contenido y la forma se combinan en la creación de una experiencia espacial precisa. El análisis del espacio urbano es coherente con lo que J. J. Gibson (1974) llama exploración o recopilación de información ambiental. Las personas exploran una secuencia de cambios en la organización del espacio, lo que permite la creación de un »mapa« del entorno. Las partes interesantes de la estructura del medio ambiente atraen la visión de los individuos, particularmente los movimientos y desplazamientos; las diferencias o ciertos detalles contienen información condensada y atraen nuestra vista, dice Gibson. Lugares y objetos definen el espacio y le dan personalidad. El espacio se convierte en lugar cuando tiene definición precisa y significado (Tuan, Y. 2003). Las cosas adquieren importancia sobre todo a través de los dictados de la cultura. El lenguaje verbal puede no coincidir con la capacidad de articular los niveles de experiencia, por lo tanto, dice Tuan, el arte y los rituales cumplen las funciones que el lenguaje verbal no puede cumplir. Las obras de arte muestran imágenes materiales que resultaron a partir de de imágenes emocionales, por lo que 
permiten la contemplación y el pensamiento. Hay aquí una interesante paradoja: la mente crea distancia y simultáneamente destruye la inmediatez de la experiencia. La reflexión sobre nuestro pasado selecciona partículas de este, obteniendo con ello la permanencia.

A. Puig (1979) afirma que los aspectos psicológicos de la percepción del espacio se relacionan con aspectos sociológicos, porque siempre parten de la percepción de las características culturales del entorno. Así las formas que percibimos son las únicas que un determinado contexto social permite. Incluso los postulados más básicos de la psicología de la Gestalt son en gran parte el resultado de »situaciones culturales «, no sólo consecuencias de nuestra capacidad de percepción. El hombre crea una especie de dialéctica entre las sucesivas percepciones. Sobre la base de las percepciones actuales y las anteriores es que establece nuevas dimensiones de percepción y atención. Las cosas muestran cierto material, cualidades y características objetivas más lo que se agrega de acuerdo con las percepciones anteriores del sujeto. Este establece las características de las formas de la naturaleza y la naturaleza crea la imagen de los seres humanos. Este proceso está influenciado por una base ideológica, un determinado contexto social, intereses conscientes e inconscientes, el espacio, el tiempo, y por numerosos factores previsibles e imprevisibles más.

El arquitecto crea la imagen de la cultura. En este proceso esta presente el medio ambiente natural y humano, lo que refleja las características funcionales de los patrones rítmicos, que definen y constituyen una cultura. Estos patrones son un complejo de la vida personal y social. El arquitecto intuitivamente detecta el ritmo cultural y trata de encontrar una forma simbólica, crea un mundo que es naturalmente complementario de cada persona: a nivel personal, esto es su casa; a nivel social, se expresa a través de edificios representativos y su entorno, dice Tuan (2003).

S. Holl (2000) dice que abrir la arquitectura a la percepción significa dejar de lado la comprensión racional para estar abierto a la intuición, que nos lleva a la naturaleza del espacio. Las perspectivas superpuestas debido a las posiciones cambiantes del cuerpo a través del espacio crean diferentes puntos de fuga. El espacio de la perspectiva, visto a través del espejo del movimiento es radicalmente diferente tanto de la perspectiva renacentista estática como de la presentación moderna, racional, positivista y axonométrica del espacio. La dinámica de una serie de perspectivas genera un espacio fluido desde el punto de vista del cuerpo en movimiento y en constante cambio de eje. La vista axial no supone una superficie de dos dimensiones, sino de tres y se manifiesta también en la fuerza de gravedad, los campos electromagnéticos, el tiempo, etc. El fenómeno de la perspectiva en movimiento es la base de la experiencia espacial.

La percepción del espacio arquitectónico requiere diferentes relaciones de cambio de tres planos: el primer plano, el plano medio y el de fondo, lo que significa mirar la distancia en una experiencia única de un cuerpo humano que ocupa un espacio determinado. La combinación entre un objeto y el campo en el que se encuentra, cambia constantemente en función de las circunstancias individuales del sujeto que percibe. Luz, color y materiales generan procesos abiertos que continuamente plantean nuevas relaciones. Por otra parte, el autor añade que en realidad, no hay otros lugares sino los que son definidos por determinados puntos. Resume así la interesante 
definición de H. Bergson, a saber, que el espacio es una combinación de tiempo homogéneo que se refleja en una dualidad: multiplicidad de puntos y corriente continúa al mismo tiempo.

La arquitectura se compone de dos términos, que dependen el uno del otro, pero que al mismo tiempo se excluyen mutuamente: la realidad de la experiencia arquitectónica y la realidad abstracta de la experiencia de la verdad absoluta, que surge de la emoción, dice B. Tschumi (2001). Ambas cosas a la vez no se pueden dar: la experiencia y el pensar lo que experimentamos. El concepto de espacio no se encuentra en el espacio mismo. El autor dice que cualquier intervención arquitectónica hoy significa siempre una combinación de elementos diferentes, organizados en categorías de un complejo proceso de relaciones maleables. El trabajo del arquitecto es por lo tanto la formulación, la invención de nuevas relaciones. La arquitectura ya no puede ligarse meramente a la composición o a la función, sino a una larga y amplia relación de variables que permiten innumerables combinaciones. La arquitectura no es un producto material estable, sino que constantemente genera nuevos eventos.

\section{Educación para la arquitectura: reciclaje del espacio urbano}

K. Lynch (1998) dice que al igual que una obra arquitectónica, la ciudad es un edificio a gran escala. La percepción del espacio de la ciudad es gradual, con intervalos de tiempo. La imagen de la ciudad es una combinación de todas las percepciones. Tan importantes son los elementos que se mueven como los inmóviles que la componen. A este autor le interesan la calidad visual de la ciudad y la "legibilidad" de los paisajes urbanos que permiten desarrollar una imagen urbana, producto de experiencias sensoriales y recuerdos, que son la base para la interpretación de cualquier información espacial. Dice que una imagen eficaz del medio ambiente ofrece fuerte apoyo emocional y confianza. Esta imagen se produce como producto del un proceso bilateral entre el espectador y el medio ambiente. El medio ambiente sugiere relaciones y distinciones y es el espectador el que elige la forma de organizar y dar sentido a lo que ve. Es por eso que las imágenes creadas por diferentes personas son diferentes. De cualquier manera, hay algo que se podría llamar »configuración básica pública«, una imagen mental de la ciudad, que es común a la mayoría de los espectadores.

Las imágenes ambientales pueden ser analizadas en términos de identidad, estructura y significado. Las imágenes eficientes tienen características distintivas. Esta es lo que llamamos identidad. Sugieren una relación espacial con el espectador y otros objetos. Contienen un significado práctico o emocional para el espectador. Es necesario tener en cuenta la calidad física de los elementos que conforman esa imagen. Deben ser lo suficientemente importantes como para permitir la identificación de la estructura del espacio y el funcionamiento de la imaginación y la »legibilidad «. Respecto del desarrollo de la relación entre el espectador de las imágenes y las imágenes visualizadas, hay dos polos sobre los que construir: por un lado, evidenciar los cambios que se generan en el medio ambiente y por el otro, ofrecer al espectador nuevos incentivos que puedan cambiar las imágenes creadas en el pasado. Esto debería ser el objetivo principal de la educación visual y artística en todos los niveles educativos. 


\subsection{Aplicación pedagógica: Métodos y desarrollo}

Las ideas presentadas hasta este punto son el apoyo teórico a una investigación pedagógica empírica sobre imagen de la arquitectura y su relación con la definición de la identificación con el espacio arquitectónico en la ciudad y las posibilidades de su reciclaje cambiando su función y su forma. La investigación fue planeada específicamente para el desarrollo de los contenidos sobre arquitectura dentro de la asignatura Educación artística, en la que los alumnos realizan sus propios proyectos en los diferentes campos de las artes visuales y del diseño espacial. Fue uno de los proyectos que se generaron a partir del programa propiciado por el Fondo europeo para el desarrollo regional titulado R.A.V.E. space (Raising Awareness of Values of Space) cuyo objetivo es la educación en el campo de los valores del espacio.

Este "momento pedagógico" es muy importante si tenemos en cuenta tanto el contexto presentado, como el papel de la educación y sus implicaciones en la formación de un individuo que mira la arquitectura con conciencia crítica. La inclusión de estos contenidos desde el principio de la escuela primaria así como la educación de los futuros arquitectos, definiendo su función como un servicio social al configurar el contexto físico y cultural de la vida, debería significar un importante reto en el campo de la pedagogía de las artes plásticas, permitiendo gran libertad respecto de los aspectos formales y creativos de la arquitectura y al mismo tiempo fomentando un gran sentido de la responsabilidad frente al espacio común.

La investigación se llevo a cabo con un grupo de 163 estudiantes del primer año de la escuela secundaria de 15 y 16 años de edad y pertenecientes a cinco escuelas de la ciudad de Ljubljana, capital de Eslovenia.

Los instrumentos de evaluación incluyeron un cuestionario introductorio para descubrir cómo y a partir de qué elementos, los estudiantes crean la imagen de un objeto arquitectónico y a partir de éste, un trabajo de diseño de una propuesta para un proyecto de reciclaje en el centro de la ciudad de Ljubljana. Esta segunda parte fue en cierto modo una realización práctica de las ideas que los estudiantes reflejaron en el cuestionario introductorio. En el mismo, los estudiantes tuvieron que responder a la siguiente proposición: "Echa un vistazo a las fotos de las fachadas de tres edificios diferentes. ¿Cuál te gusta más y por qué?, ¿Cuál es en tu opinión, el más apto para nuestro entorno, si tienes en cuenta los materiales con que se construyó y por qué? Las imágenes a elegir presentaban las siguientes posibilidades:

- A: Tschumi, Parque de la Villette, Paris, 1984, (ejemplo de arquitectura "high tech").

- B: Reichlin y Reinhart, casa Tonini, Torricella, 1974, (ejemplo de arquitectura postmoderna).

- C: Barragán y Goeritz, Torres Satélite, Ciudad de Méjico, 1957, (ejemplo de arquitectura moderna).

Es importante señalar que los estudiantes no estaban familiarizados con las imágenes propuestas, ya que pertenecen a entornos muy diferentes de los que ellos conocen (Frampton, K. 1992). Manipular con ellas significó un proceso de análisis, abstrac- 
ción y evaluación, el resultado del cual les permitió aplicarlas al contexto concreto en el que viven.

En la segunda fase de la investigación y después de discutir acerca de las características específicas del espacio en un punto central de Ljubljana - Plaza Prešeren cada alumno recibió un dibujo incompleto del sitio. La tarea que cada alumno realizó consistió en sugerir una nueva función y una nueva forma para la "ocupación" de ese espacio de la ciudad. Los alumnos podían dibujar, pintar, usar collage o cualquier otra técnica de representación bidimensional.

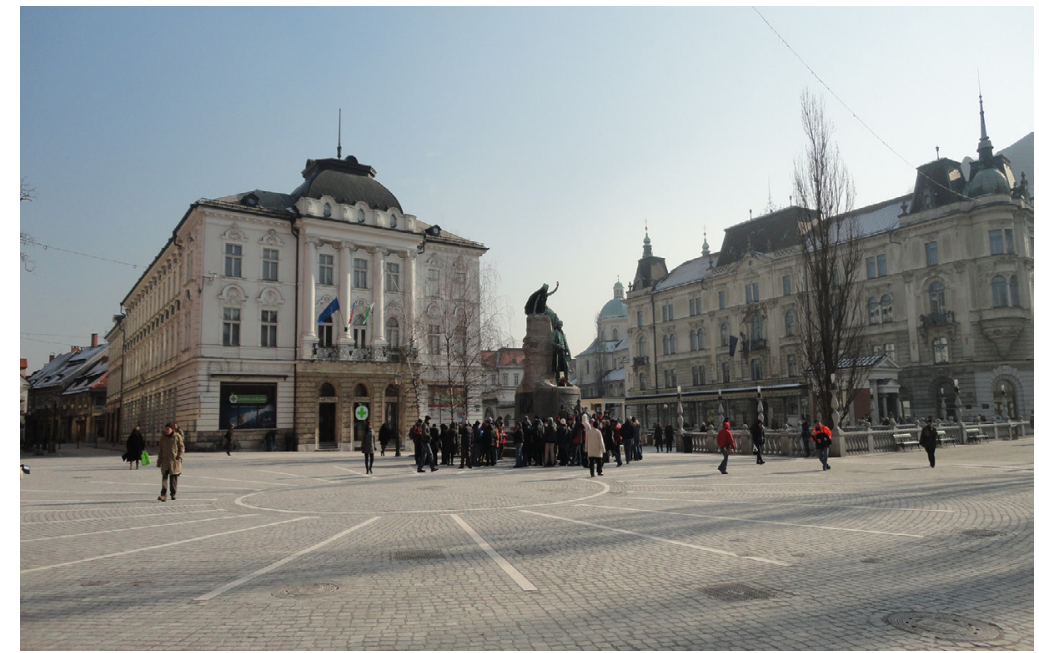

Figura 1. Plaza Prešeren en el centro de Ljubljana. Fotografía: Beatriz Tomsic Cerkez

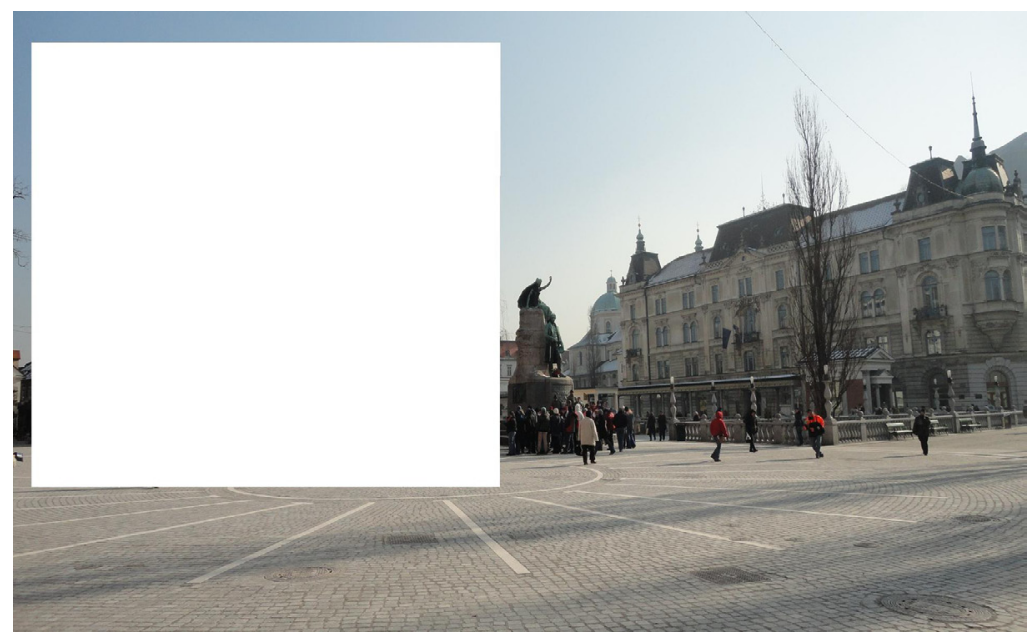



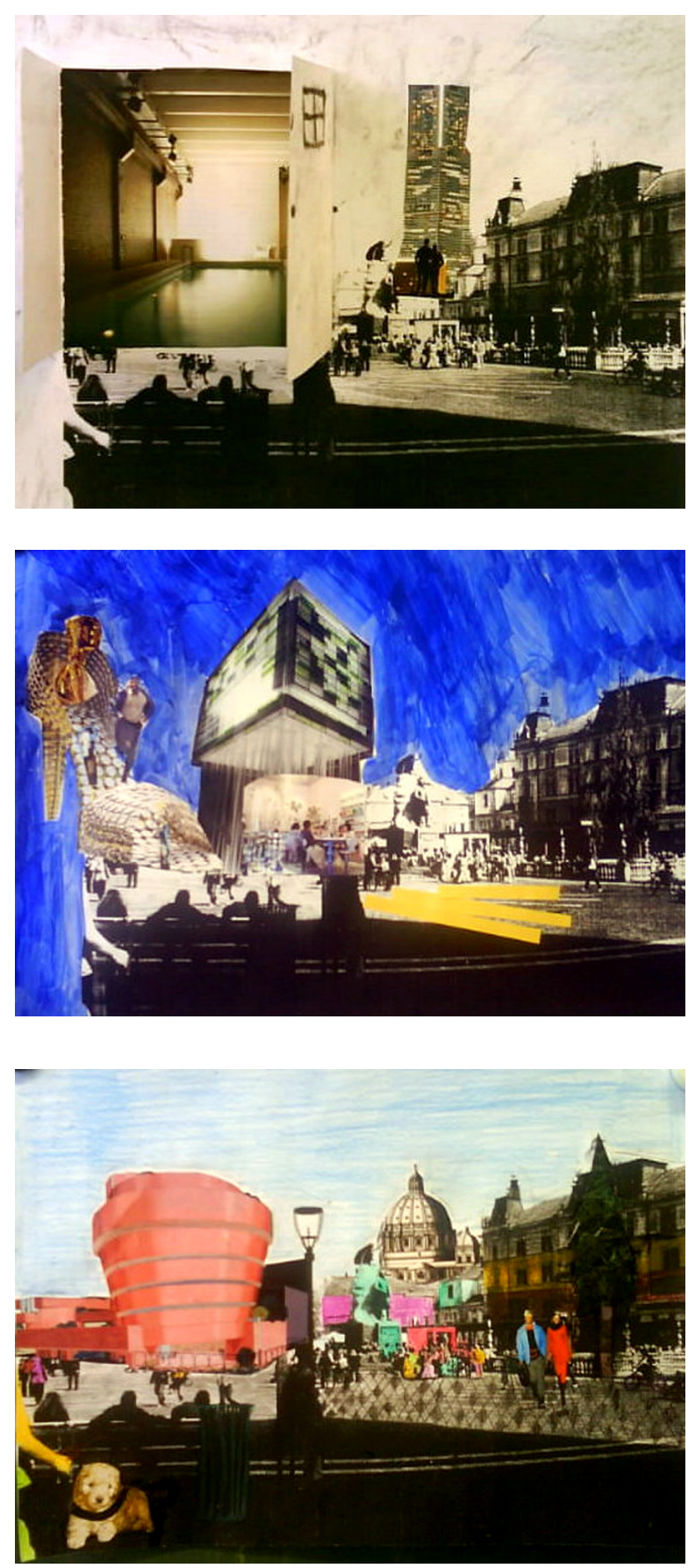

Figuras 3a, 3b, 3c. Ejemplos de las propuestas de una nueva forma para la "ocupación" de espacio de la ciudad, realizadas por tres de los alumnos. Fotografías: Beatriz Tomsic Cerkez 


\subsection{Resultados}

Las respuestas al cuestionario introductorio fueron analizadas en dos fases: en primer lugar, consideramos el número de respuestas - el número de puntos que alcanzó cada imagen; en segundo lugar, se analizó el tipo de información que figuraba en las explicaciones de los estudiantes. A partir de estos datos intentamos elaborar una interpretación cualitativa de las respuestas.

Los resultados fueron los siguientes: la imagen A fue elegida por el 4,49 por ciento de los estudiantes; la imagen B, por el 48,31 por ciento y la C por el 47,20 por ciento. En cuanto a las razones de la elección, los estudiantes que optaron por la imagen B, declararon que "no se diferencia de los alrededores", "es hermosa", "tiene bonitos colores", "debido a la forma de las ventanas y la cubierta", "debido a que se ve equilibrada", "el entorno natural del edificio es exuberante y bello." Los estudiantes que eligieron la imagen C manifestaron que "contrasta con su entorno", "es especial y diferente". La mitad de los estudiantes dijo que "les gusta porque se ve moderna y contemporánea", muchos dijeron que "les recuerda a una ciudad moderna y grande." El 39, 57 por ciento de los estudiantes que optaron por la imagen C declararon que "les gusta porque se ve monumental." En cuanto a la cuestión de los materiales utilizados en la construcción, los estudiantes que optaron por las imágenes $\mathrm{B}$ y C respondieron prácticamente con declaraciones muy similares: "son tradicionales", "son de nuestro entorno ", "son hermosos", "son estáticamente apropiados", "contrastan/ no contrastan con el entorno", "son contemporáneos" etc.

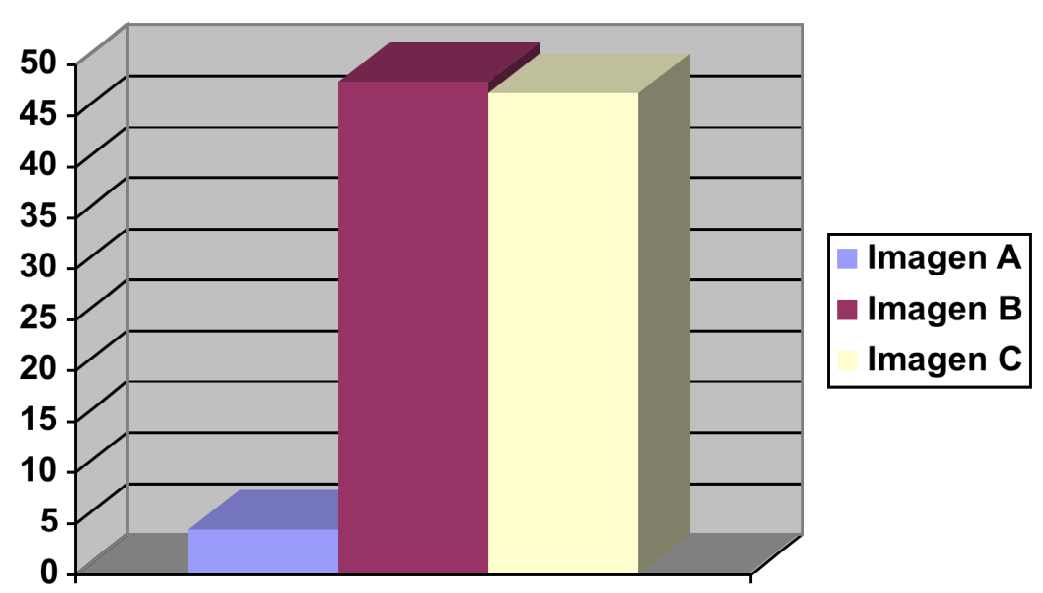

Figura 4. Resultados de la elección de las imágenes en el cuestionario introductorio

Respecto de los resultados de este cuestionario, obviamente no es posible llegar a conclusiones definitivas ya que se necesitaría mucha más información. Sin embargo, la cuestión analizada fue particularmente interesante porque se centró en las características de la recepción de la imagen de la arquitectura a los ojos de los estudiantes. A pesar del hecho de que las cifras muestran una oposición conceptual, las respues- 
tas son muy similares y reflejan una actitud especial en relación a los valores que la arquitectura fomenta en los mismos: es en cierto modo la materialización de metas y deseos románticos: "el buen salvaje" escondido en una cabaña hermosa o el sueño de progreso, modernidad y monumentalidad, como condición para la aceptación de uno mismo. En este punto, el equilibrio que nombramos al comenzar este texto, se convierte en un hecho que importa mucho. En realidad, el equilibrio implica la preexistencia de un par dialéctico, una espacie de contrapeso. En el caso presentado, los estudiantes hablan de "una imagen romántica que promueve deseos de cosas que no poseen." Lo mismo podría aplicarse a la "monumentalidad." En cualquier caso, queda reflejado, que siempre hay un elemento que falta, que genera un vacío y que debemos prestar atención a qué tipo de ideas se oponen en nuestro análisis (Hiss, T. 1991, Livingston, R. 1993, Willis, D. 1999). Para hacer más comprensible esta formulación, es importante tener en cuenta que la ciudad de la que hablamos es relativamente pequeña, ya que tiene aproximadamente 400.000 habitantes, hace solo 20 años que es capital de un también pequeño país, que es el único de la ex Yugoslavia que luego de la guerra, ha pasado a ser parte de la Unión Europea. Las imágenes de Ljubljana se contrastan continuamente con las de otras ciudades y capitales europeas, que pasan a ser la encarnación de la ciudad ideal, bella y monumental.

Los ejercicios de la segunda fase de nuestra investigación muestran una gran variedad de ideas de los alumnos. Los mismos fueron revisados por tres evaluadores independientes para asegurar la objetividad de la evaluación. La evaluación se realizo en base a un formulario común para los tres evaluadores, que contenía los siguientes criterios de valoración: tipo de relación con el entorno, características formales, función propuesta, originalidad, uso de las técnicas artísticas elegidas.

El resultado del análisis cualitativo de las propuestas de los alumnos en la segunda fase de la investigación según los evaluadores revela que en el 89 por ciento de los casos se trata de una imagen, que al igual que en las respuestas al primer cuestionario, expresa deseos utópicos acerca de una ciudad que carece de algunas de las características esperadas; por ejemplo la monumentalidad, que es común a la mayoría de las propuestas. Solamente el 11 por ciento de los alumnos generó propuestas que podríamos denominar como "realistas", es decir, con potencialidad de ser materializadas creando equilibrio entre la tradición y la novedad. Probablemente estas respuestas están relacionadas con la imagen de Ljubljana, que no es monumental sino todo lo contrario. Otra característica formal de la mayoría de los trabajos es el contraste con el entorno, ya sea a través de colores, materiales y formas, lo que se puede apreciar en la figura 3. En cuanto a las funciones elegidas por los alumnos para los edificios de ese lugar específico, es importante destacar que la absoluta mayoría, el 100 por ciento, previó actividades de tipo colectivo (galería, teatro, centro comercial etc.) para sus edificios, demostrando que en general entienden y respetan la naturaleza del espacio público en la ciudad. Las propuestas fueron en general, muy originales y muy heterogéneas, demostrando que en la mayoría de los casos, los estudiantes no partían tanto de la imagen del entorno, como de la idea del evento que debe crear la arquitectura. Para realizar los trabajos, la mayoría de los alumnos eligieron técnicas artísticas combinadas de pintura, dibujo y collage, logrando imágenes muy expresivas. 


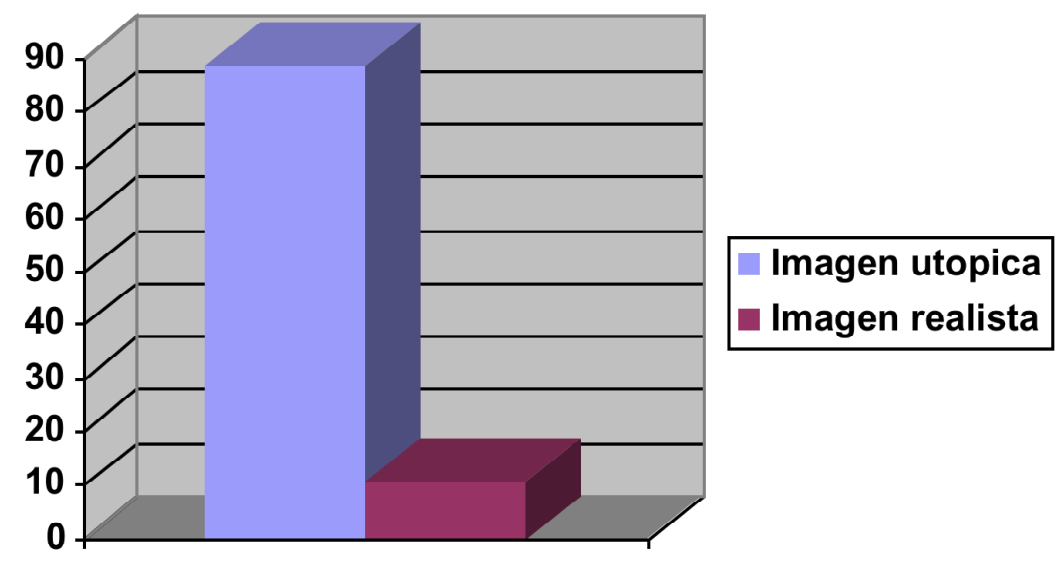

Figura 5. Resultado del análisis cualitativo de las propuestas de los alumnos en la segunda fase de la investigación

Nuestro principal objetivo fue abrir caminos de pensamiento reflexivo y crítico sobre los valores de la cultura, relacionados con la arquitectura y el espacio urbano. Este fue el primer paso en la creación y adquisición de conocimientos adecuados sobre el medio ambiente y el desarrollo sostenible de la arquitectura de la ciudad.

Este ejercicio fue también una introducción a la problemática del reciclaje del espacio arquitectónico en el aspecto formal y del espacio urbano, especialmente en cuanto a su función. El siguiente paso sería pensar en la transformación de un edificio preexistente, lo que obviamente no es tarea fácil teniendo en cuenta las posibilidades técnicas y los conocimientos de los alumnos del primer año de la escuela secundaria, haciendo hincapié en los aspectos que se relacionan con el desarrollo sostenible en el campo del arte y la cultura en general, así como de la arquitectura en particular.

\subsection{Discusión}

Es posible concluir que los resultados de los ejercicios propuestos a los alumnos muestran un vacío que podría ser eventualmente llenada por la arquitectura. El arquitecto puede convertirse en este caso en el realizador de un sueño, llenando los espacios en blanco de lo que los individuos ven como una falta de elementos que den forma positiva a su identidad, así como a la identificación con un espacio específico. Esto también nos ayuda a explicar la realidad de la arquitectura de hoy: renegación del racionalismo, aplicación de ciertos modelos extranjeros sin aceptar otros que podrían ser más ajustados en un entorno específico, crítica a la implementación de estrategias globales sobre todo porque hay una necesidad de reemplazar la falta de experiencia local (Vidler, A. 2001).

Probablemente una de las razones es que el Postmodernismo, que en realidad nació en el campo de la arquitectura y es a menudo caracterizado por la búsqueda de teorías locales y contingentes a diferencia de la gran y totalizadora teoría de la mo- 
dernidad ha adoptado formas muy específicas en nuestro contexto (Rossi, C. 1971, Grosz, E. 2001).

El pensamiento reciente acerca de la reposición de la arquitectura a las ciencias sociales (Beck, U., Giddens, A., Lash, S. 1994), de modo que el desarrollo de la arquitectura pueda ser visto en relación a otras áreas de la cultura, abre nuevas preguntas y anima la ubicación de nuevos pares dialécticos que tienen en cuenta el equilibrio entre lo individual y lo social, lo histórico y lo contingente, lo local y lo extranjero, el estilo y el lugar, lo utópico y lo real etc. Planteada en estos términos, la cuestión de la arquitectura moderna, una vez articulada dentro de lo cosmopolita, se mueve más allá de la imagen y al mismo tiempo que crea la imagen de la arquitectura, que por supuesto nunca es mera apariencia, simple imagen, dice A. Benjamin (2003). Este es en mi opinión un buen punto de partida para la reflexión sobre la aplicación de estrategias concretas en la educación artística, concretamente en el campo de la arquitectura.

\section{Conclusión: La conservación de la energía cultural}

La evolución de nuestras sociedades se refleja en los tipos de nuestros edificios y en los estilos de nuestras construcciones. Esta relación da los edificios más antiguos un carácter y un valor con los que nos identificamos. Sin embargo, la mentalidad empresarial muchas veces no parece apreciar el valor económico a largo plazo de los edificios ni su espíritu cultural. Esta devaluación es característica de la llamada globalización y ya es en parte expresada por las generaciones más jóvenes, como testificó nuestro experimento. Como sostiene B. Tschumi (2001), la arquitectura no se define más solamente en el aspecto formal y funcional sino que es ante todo un evento dinámico.

La famosa cita de L. Sullivan "la forma sigue a la función", parece haberse convertido en una filosofía anticuada. Muchos edificios modernos no reflejan la riqueza y la complejidad de la evolución cultural. Pocos diseñadores contemporáneos parecen valorar el aspecto emocional del espíritu de la arquitectura.

Cuando un edificio de mérito histórico se conserva o restaura para su reutilización adaptativa, su energía cultural también se recicla. Es muy probable que la vieja estructura fuera colocada estratégicamente para obtener las mejores vistas y la orientación óptima respecto del sol y el viento. Seguramente fue construido para garantizar la seguridad de sus ocupantes, logrando un equilibrio especial entre la masa construida y los espacios abiertos. Los viejos edificios preservan la cultura y la identidad local y crean sentido de pertenencia. En cierto modo, nosotros reciclamos la energía de los recursos humanos junto con la energía material. Mantenemos vivo el pasado para que forme parte del futuro creando conexiones importantes en el tiempo.

La dicotomía de las ideas y los hechos en el campo de la arquitectura es también la razón por la cual podemos afirmar que la educación artística a principios del siglo XXI se enfrenta a nuevos retos. A juzgar por los resultados de nuestra investigación, podríamos afirmar que la relación de nuestros alumnos con su entorno tiene varias facetas, que en algunos casos son incompatibles y por eso se convierten fácilmente en un desafío para el pedagogo. Revelan un deseo quizás inconsciente de utopia y 
monumentalidad que supone una valoración más positiva del entorno que la que se genera en la ciudad de la realidad diaria. Por otro lado, como lo demuestran al menos parcialmente los resultados del cuestionario de la primera fase de la investigación, un buen porcentaje de los alumnos al mismo tiempo apuestan al reconocimiento del valor de un entorno formalmente equilibrado y respetuoso de la tradición. Todos demuestran tener conciencia de la pertenencia colectiva a la ciudad.

Es obvio que una visión global sobre el proceso pedagógico de la educación artística exige la inclusión de un modo nuevo, específico de evaluación precisa de las actividades que permitan a los estudiantes experimentar la arquitectura desde diferentes puntos de vista: como individuos críticos y también como productores. De hecho, la comprensión del pasado, así como las intervenciones contemporáneas exigen un conjunto de experiencias rico y complejo, lo cual es uno de los principales objetivos de la educación en todos los niveles.

Las barreras que una alguna vez separaban a los diferentes campos del arte ya no existen. Las nuevas tecnologías introdujeron una gama completamente renovada de experiencias y posibilidades. Los dinámicos cambios socioculturales contemporáneos afectan a las expresiones artísticas de todo tipo, también a la arquitectura; los debates sobre la identidad cultural de los grupos minoritarios, las cuestiones de identidad nacional, los cambios rápidos en el campo de la tecnología y el advenimiento de la filosofía postmoderna de la fragmentación y la pluralidad han transformado al arte, la arquitectura y la educación. Estas transformaciones afectaron también la forma en que aprendemos sobre arquitectura. El desarrollo intensivo de nuevos caminos en la educación artística se demuestra en el hecho de que muchos autores promueven en forma creciente el campo de los estudios de la cultura material, como una base teórica viable y una orientación práctica para la educación artística. Esto permite adoptar formulaciones integrales de largo alcance y prácticas que puedan ser críticamente examinadas con métodos interdisciplinarios, multidisciplinarios y transdisciplinarios asociados a estudios de la cultura material. La orientación multisensorial de los estudios de la cultura material es congruente con las tendencias contemporáneas en las artes, la arquitectura y la cultura y permite a los educadores desarrollar la imaginación estética necesaria para fomentar en sus alumnos la creación de experiencias culturales únicas, así como para apreciar y comprender la historia de las artes y por ende, la historia de la arquitectura de manera holística e integrada (Blandy, D., Bolin, P. E. 2003, 246-263).

Entre los objetivos de una educación artística viable se debe considerar el compromiso con problemas auténticos y reales en nuestras sociedades. Una de ellas es la toma de conciencia acerca de las características del entorno construido. Nuestras ciudades son, de hecho, los resultados de capas de tiempo y espacio que funcionan como unidades de experiencias espaciales en la vida cotidiana. Los edificios más antiguos son a menudo hitos urbanos. Son puntos de referencia icónica y su simple presencia pone de manifiesto un conjunto de significados únicos para la memoria colectiva de una sociedad. Compuesto por fuertes elementos formales y simbólicos, son fácilmente reconocibles. Incluso aunque se utilicen para su función inicial o primaria, invitan a los transeúntes a su contemplación. Su demolición en muchos casos dañaría la imagen de la ciudad y la memoria. Este tema - el reciclaje de espacios arquitectóni- 
cos - debería ser una de las importantes tareas auténticas que se podrían practicar en el contexto de la educación plástica con el fin de desarrollar la conciencia acerca de la idea de que es posible recuperar los objetos de relieve en el contexto urbano que ya no están en uso, para asignarles un nuevo uso asociado a los contenidos de la memoria colectiva. El hincapié en los valores de la memoria colectiva es, sin duda, otro de los objetivos claves de la educación artística. La educación artística es una forma de promover experiencias de aprendizaje, de desarrollar la comprensión y la creación de una representación holística del mundo, así como del pensamiento creativo y crítico a través de la estética y de las dimensiones sociales (Purini, F. 1986). En efecto, una comprensión global de nuestro pasado y de nuestro mundo contemporáneo exige este conjunto de complejas experiencias de integración, lo que también es uno de los principales objetivos de la educación en general en todos los niveles.

\section{Referencias}

Anderson, M. J. (2002). Sustainable development. WFF Voices Online Edition, Vol. XVII, 1, consultado el 22 de marzo de 2009.

Beck, U.; Giddens, A. y Lash, S. (1994). Reflexive Modernization - Politics, Tradition and Aesthetics in the Modern Social Order. Standford: Stanford University Press.

Benjamin, A. (2003). The Style of Architecture. En B. Tschumi e I. Cheng, (eds.) The State of Architecture at the Beginning of the 21st Century (pp. 44-45). Nueva York: The Monacelli Press, Inc.

Blandy, D. y Bolin, P. E. (2003). Beyond Visual Culture: Seven Statements of Support for Material Culture Studies in Art Education. Studies in Art Education, 44, 3, 246-263.

Crary, J. (2001). Suspensions of Perception - Attention, Spectacle, and Modern Culture. Cambridge, Massachusetts: The MIT Press.

Frampton, K. (1992). Modern Architecture, A Critical History. Londres: Thames and Hudson.

Gibson, J. J. (1974). La percepción del mundo visual. Buenos Aires: Ediciones Infinito.

Gieidion, S. (2008). Space, Time and Architecture: The Growth of a New Tradition. Cambridge, Massachusetts: Harvard University Press. (Versión original 1941).

Grau, O. (2004). Virtual Art. From Illusion to Immersion. Cambridge, Massachusetts: The MIT Press.

Grosz, E. (2001). Architecture from the Outside. Cambridge, Massachusetts: The MIT Press.

Hiss, T. (1991). The experience of place, A new way of looking at and dealing with our radically changing cities and countryside. Nueva York: Random House, Inc.

Holl, S. (2000). Parallax. Nueva York: Princeton Architectural Press.

Brunel, S. (2008). A qui profite le développement durable. Paris: Presses Universitaires France.

Livingston, R. (1993). Arquitectura y autoritarismo. Buenos Aires: Ediciones de la Flor.

Lynch, K. (1998). La imagen de la ciudad. Barcelona: Editorial Gustavo Gili, S.A. 
Puig, A. (1979). Sociología de las formas. Barcelona: Editorial Gustavo Gili, S. A. Purini, F. (1986). La arquitectura didáctica. Murcia: Consejería de cultura y educación de la comunidad autónoma.

Ricoeur, P. (1985). Lectures on Ideology and Utopia. Nueva York: Columbia University Press.

Rossi, C. (1971). Arquitectura como semiótica. Buenos Aires: Ediciones Nueva Visión.

Tschumi, B. (2001). Architecture and Disjunction. Cambridge, Massachusetts: The MIT Press.

Tuan, Y. (1977). Space and Place - The Perspective of Experience. Minneapolis: University of Minnesota Press.

Vidler, A. (2001). Warped Space - Art, Architecture, and Anxiety in Modern Culture. Cambridge, Massachusetts: The MIT Press.

Willis, D. (1999). The Emerald City and Other Essays on the Architectural Imagination. Nueva York: Princeton Architectural Press. 